\title{
Implementation of a Surgery Congress for Medical Students to Learn Transversal Competences. A Case of Student-Led Teaching Activity
}

\author{
Borja Herrero de la Parte 1,2,*iD, María Santaolalla-Sánchez ${ }^{3}$, Francisco Javier Santaolalla-Sánchez ${ }^{3}$, \\ Ignacio García-Alonso ${ }^{1,2}$, Francisco Santaolalla ${ }^{2,4,5}$ and Ana Sánchez del Rey ${ }^{4}$ \\ 1 Department of Surgery and Radiology and Physical Medicine, University of the Basque Country, \\ ES48940 Leioa, Spain; ignacio.galonso@ehu.eus \\ 2 Biocruces Bizkaia Health Research Institute, ES48903 Barakaldo, Spain; francisco.santaolalla@ehu.eus \\ 3 Faculty of Medicine and Nursing, University of The Basque Country, ES48940 Leioa, Spain; \\ msantaolalla003@ikasle.ehu.eus (M.S.-S.); fsantaolalla003@ikasle.ehu.eus (F.J.S.-S.) \\ 4 Department of Dermatology, Ophthalmology and Otorhinolaryngology, University of the Basque Country, \\ ES48940 Leioa, Spain; ana.sanchezdelrey@ehu.eus \\ 5 Osakidetza Basque Health Service, Basurto University Hospital, Department of Otorhinolaryngology, \\ ES48013 Bilbao, Spain \\ check for \\ * Correspondence: borja.herrero@ehu.eus
}

updates

Citation: Herrero de la Parte, B.;

Santaolalla-Sánchez, M.;

Santaolalla-Sánchez, F.J.;

García-Alonso, I.; Santaolalla, F.; Sánchez del Rey, A. Implementation of a Surgery Congress for Medical Students to Learn Transversal Competences. A Case of Student-Led Teaching Activity. Educ. Sci. 2021, 11, 536. https://doi.org/10.3390/ educsci11090536

Academic Editors: Maria

Alessandra Sotgiu and Bernard John Moxham

Received: 15 July 2021

Accepted: 7 September 2021

Published: 14 September 2021

Publisher's Note: MDPI stays neutral with regard to jurisdictional claims in published maps and institutional affiliations.

Copyright: (c) 2021 by the authors. Licensee MDPI, Basel, Switzerland. This article is an open access article distributed under the terms and conditions of the Creative Commons Attribution (CC BY) license (https:// creativecommons.org/licenses/by/ $4.0 /)$.
Abstract: Background: A dynamic training approach close to clinical work and research is highly requested by health sciences students. The aim of this paper is to present the organizational model of a student-promoted and student-managed surgical congress that encourages the acquisition of transversal competencies among the students in charge of the organization of the Congress. Methods: A two-day surgical congress for medical students organized by themselves was held. Each day comprised two separate sections corresponding to different surgical specialties; sections included three types of activities: conferences, round tables with guest professors, and practical workshops. Once the Congress had finished, an online survey was carried out to evaluate 10 items scored from 1 to 4 . To assess the acquisition of transversal competences among the students organizing the congress, three evaluations were carried out by the professor involved in the organization of the congress. Results: The congress had great acceptance among the students, filling 150 available places with an attendance rate of $100 \%$. The survey showed a high assessment of the subjects $(3.48 / 4)$, conferences (3.48/4) and workshops (3.27/4). Evaluation of the round tables was significantly lower (2/4). A total of $99 \%$ considered the congress to have been useful in its formation process and $100 \%$ would recommend it. The grade of transversal competences among the students organizing the congress showed a significant increase between the first and the third evaluation, being between 1.24 and 7.25 times higher. Conclusions: the student-led student surgical congress is a well-evaluated activity for medical students, and promotes, among its organizers, the acquisition of transversal competences.

Keywords: transversal competences; skills; medical degree; congress; medical teaching

\section{Introduction}

The World Conference on Higher Education held in Paris in 1998 was the trigger for a process of change in the paradigm of education for European universities. Its publication in 1999 was a milestone in the beginning of transformation of university education, focusing on the development of transversal competences, in parallel with the acquisition of the curricular objectives of the different undergraduate studies [1]. Therefore, competencybased learning is not a new concept originating in the Bologna process; rather, the first references appeared in the 1960s and 1970s, and re-emerged strongly in the late 1980s and early 1990s. The reference to some competences as transversal indicates that they extend beyond the area of knowledge of the subject to which it belongs and that their contents 
will be defined by the job market and the social environment that the graduates will join once they finish their academic training [2].

Traditionally, teaching and learning in the medical field have been focused, almost exclusively, on achieving the specific skills of the discipline or medical science, obviating the need to implement those with transversal features. However, because of the Paris conference, the implementation of the Bologna Plan, and the establishment in 2010 of a European Higher Education Area, there has been a phenomenon of review and adaptation encouraging the incorporation of transversal competences in the new curricula, restructuring the teaching-learning process, with the student being its main actor. Therefore, on the basis of the five competency domains collected by the III Conference of Higher Education of the UNESCO Asia-Pacific Region [3]—interpersonal skills (in relation to other people), intrapersonal skills (self-control, autonomy and motivation), critical and innovative thinking, global citizenship, and media and information literacy-the University of the Basque Country developed a set of eight transversal competences [4]. These domains or capacities must be developed in the individual themselves, combining skills and attitudes based on values and personal confidence [5].

To this end, the idea of organizing and promoting a congress themselves came up among the students of the Faculty of Medicine and Nursing of the University of the Basque Country. It had to be an activity that would provide incentive and motivation while, at the same time, allowing the transversal development of the aforementioned competences. With this purpose, the first Congress of Surgery for Medical Students was organized in the 2016/2017 academic year [6], with three consecutive annual editions having been held to date $[7,8]$. The implementation of these events forces students to develop, among others, the capacity for leadership, organization (individual and collective), teamwork, autonomy, and critical reflection. In this way, the congress sought to promote participation in an educational, instructive, enriching and high-quality event while, at the same time, stimulating personal initiative and professional interest in the surgical field. The aim of this work is to present the organizational structure of the Congress of Surgery for medical students, organized by themselves, analyzing the degree of satisfaction of the attendees, as well as evaluating how the organization of the congress promotes the acquisition of transversal competences among the student members of the Organizing Committee.

\section{Materials and Methods}

To organize each edition, at the beginning of each academic year (in the month of September), approximately 5-6 months before the Congress was held, an Organizing Committee of the Congress was constituted; it consisted of 5-7 members, of which 1 was a professor in the Department of Surgery, teaching in the Medicine degree; the rest of the members were students of various courses of the degree in Medicine. The major burden of organization and staffing was assumed by the students. The students themselves promoted the activities and proposed the initial requirements, whether in terms of staff, logistics, funding or technical aspects (reservation of facilities, provision of fungible material for the workshops, provision of medical equipment (for example, ultrasound equipment)) necessary to carry them out.

The students themselves were also in charge of conducting and teaching the practical workshops; for this purpose, students from the third and higher grades were recruited. Previously, all of them had acquired the necessary technical knowledge to develop the courses with ease. When skills had not yet been learned as part of the academic curriculum (e.g., laryngeal dissection and tracheotomy), the students in charge of teaching them were trained by the specialist professors in the area in the months prior to the Congress; in order to be able to teach the workshops, the students had to obtain the approval of the specialist professors in the area. Approximately 30 students were involved in teaching the practical workshops ( $2-3$ students in each workshop).

The faculty member's role on the Organizing Committee was to supervise or coordinate the activities as a whole. In this way, the professor played a role as a knowledge 
facilitator, rather than occupying the traditional role of a transmitter of knowledge, with the students assuming an active role in their formation. The task of the professor was to validate the activities from an organizational point of view, as well as to modify or adapt them to the curriculum of the degree in Medicine; none of the activities (lecture, workshop or round table) were carried out without the approval of this faculty member. In parallel, a Scientific Committee was also constituted, which served as a consultant. This Committee consisted of specialists in each of the different medical fields in which the workshops/conferences were subdivided; they were contacted when searching for specialists who could participate as invited speakers in the proposed conferences, as well as for the inclusion of the most appropriate medical/academic contents for each workshop.

To ensure the success of the organization and execution of the congress, the student members of the Organizing Committee met monthly with the professor member of the Organizing Committee. The tasks necessary for carrying out each practical workshop or conference (contacting the speakers, searching for material, etc.) were divided among the students and, at each meeting, they reported on the degree of achievement of the objectives established for each of them according to the different stages of organization of the congress, as well as the difficulties experienced (if any). During these meetings, the professor in charge took the opportunity to evaluate the transversal competences acquired, according to the rubric indicated in Table S1 (Supplementary Materials). This evaluation was carried out at the first meeting, an intermediate meeting and at another meeting after the congress. The evaluation was carried out individually, for each of the student members of the Organizing Committee, and then the mean of each of the three evaluations was calculated and plotted on a radar chart.

In the first edition, the surgery congress for medical students took place on two consecutive days, structured in 3 types of activities according to their typology: plenary sessions or conferences, round tables and debate, and practical workshops. The first two were intended to encourage analysis and debate among attendees and invited speakers. On the other hand, and taking advantage of the fact that surgery is a highly practical discipline, interactive practical workshops allowed the development of communication, leadership and teamwork skills. According to the differences in the grade of surgery training of the enrolled students, including students from the first to the sixth degree year, the practical workshops were divided into two itineraries, so that the subject was adapted to their academic level training. Those students who attended the congress and belonged to the first or second year of the degree in Medicine were automatically assigned to itinerary A, while the rest of the attendees (from the third to the sixth year) were assigned to itinerary B.

In the last edition of the congress in the 2018-2019 academic year, thematic Section 1 of the first day included the specialties of Neurosurgery and Vascular Surgery. Two conferences were given: "Neurosurgery yesterday, today and tomorrow" and "Vascular Surgery, a risky surgery?" As practical workshops associated with this thematic section, a "suture" workshop was held for itinerary " $\mathrm{A}$ " (first and second grade years), while itinerary " $\mathrm{B}$ " did the same with a "brain dissection" workshop. In the second section, the specialty of Otorhinolaryngology was addressed. Two conferences, "Challenges and future of Otorhinolaryngology in the XXI century" and "Applications of Biomedical Research in Surgery", served to conceptualize the clinical future of the specialty, as well as its research areas. The workshops carried out in this section consisted of an "Ear, nose and throat basic exploration" gymkhana for the first itinerary (A) and a "laryngeal dissection with tracheostomy" workshop for the second itinerary (B). An ear, nose and throat basic examination gymkhana was organized in 10 stations: audiological tests and oropharyngeal examination, otoscopic examination, cranial radiological images, and head and neck ultrasound, among others, were performed. In the " $\mathrm{B}$ " itinerary workshop, fiberoptic laryngoscopy, tracheostomy and neck dissection simulations were performed in a demo model and in a lamb's larynx. The first day concluded with a round table discussion about the topic "Challenges in Biomedical Research", in which different level researchers (basic, clinical and translational) participated. 
The second day was structured around Traumatology and General Surgery as the thematic sections, with two conferences being given in each section: "The knee in the athlete" and "The importance of Radiology" in Traumatology, and "Kidney transplantation" and a "Party conference", with the aim of promoting communication skills, in General Surgery. Workshops proposed for the Traumatology section were "placement of bandages and casts" and "resolution of clinical radiology cases" for the " $\mathrm{A}$ " itinerary and "shoulder and knee ultrasound" for route B. For the workshops included in General Surgery, itinerary "A" performed a rotation of "surgical skills: microsurgery, laparoscopy, hand washing and operating room preparation", while the "B" itinerary finished the journey with a "kidney dissection" workshop on pig specimens. To close the congress, some recent young resident doctors of the University Hospitals associated with the University of the Basque Country participated in a round table titled "Surgery seen by resident doctors".

In the third edition of the congress, 150 places were offered, which were open to any student of the degree in Medicine. Registration was performed through an online form using the Google Forms platform, including fields for filling in personal data (name and surname), in addition to the selection of the congress itinerary according to the course in which students were enrolled. After the congress, an anonymous online satisfaction survey was carried out with 10 items (scored from 1 to 4 , where 1 was the lowest and 4 was the highest; no neutral responses were allowed) using the same platform (Table 1).

Table 1. Ten-item questionnaire used to evaluate the satisfaction of Congress attendees.

\begin{tabular}{ccc}
\hline Item & Question \\
\hline 1 & Academic Course & Answer \\
\hline 2 & Itinerary & Gender \\
\hline 3 & On a scale of 1 to 4, how would you rate the conferences? Provide an individual response to each of the \\
conferences you attended.
\end{tabular}

The data were processed with GraphPad Prism $8^{\mathrm{TM}}$ software to obtain descriptive statistics for each activity carried out during the congress (mean and standard deviation), as well as for the evaluation of transversal competencies among the student members of the organizing committee. These data were then subjected to an analysis of variance for matched data (Friedman test), after checking that the data did not conform to a normal distribution, and Dunn's multiple comparisons test. A minimum significance level of $p<0.05$ was accepted.

\section{Results}

All of the 150 places offered in the Congress of Surgery for Students sold out on the first day of the registration period, year after year, running out in less than an hour in the third edition. For the last edition, the attendance verified through the signatures registration and delivery of credentials was $97.3 \%$ (146 students). Participants in the congress were $75 \%$ women (110) and $25 \%$ men (36).

Most of the congress participants were first- and second-year students, $48.64 \%$ (71) and $35.62 \%$ (52), respectively. Students in the third, fourth, fifth and sixth years accounted for, respectively, $8.9 \%$ (13), $2.74 \%$ (4), $3.42 \%$ (5) and $0.68 \%$ (1), Figure $1 \mathrm{~A}$. According to the itinerary carried out by the students, we observed that the number of students enrolled 
in the " $\mathrm{A}$ " itinerary $102(70 \%)$ was more than double that enrolled in the " $\mathrm{B}$ " itinerary (Figure 1B).

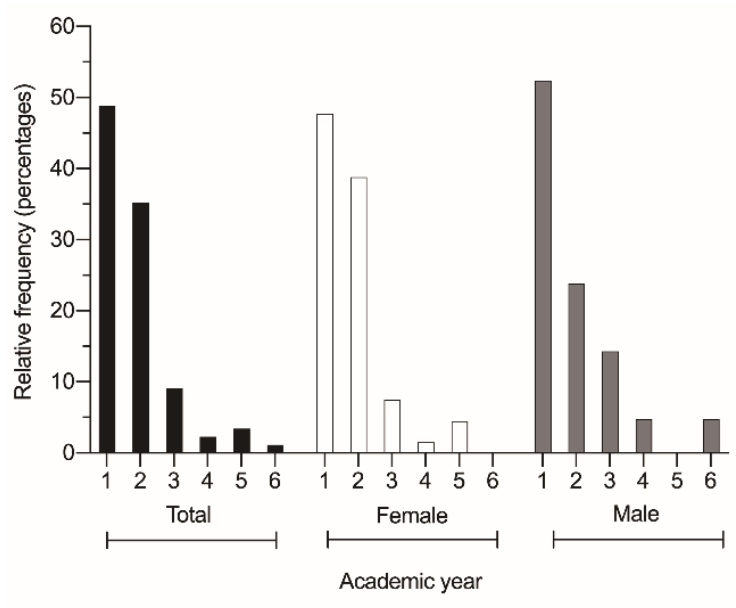

(A)

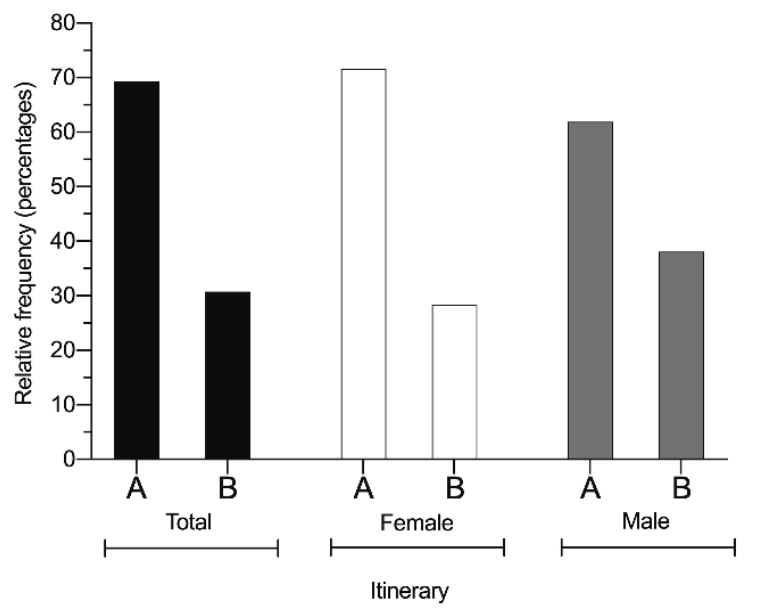

(B)

Figure 1. Histogram of relative frequencies of congress attendees according to the academic year of medicine they were attending (A) and according to the itinerary to which they were assigned (B): itinerary " $\mathrm{A}$ " (first- and second-year medical students) and itinerary "B" (third- to sixth-year medical students). Relative frequencies are shown according to the gender indicated on the registration form (female (white) or male (grey)) or both together (black).

Global assessment of conference topics was $3.55 \pm 0.55$ (out of 4). Analyzing each conference according to its contents, we verified that the topics with the highest scores were Neurosurgery $3.51 \pm 0.63$ and the party conference $3.59 \pm 0.75$; by contrast, the worst-rated conferences were Trauma and Orthopedic Surgery and Biomedical Research (round table), $2.58 \pm 0.83$ and $2.3 \pm 0.9$, respectively (Table 2 ).

Table 2. Score obtained in each of the activities carried out in the third edition of the Surgery Congress for Medical Students. Data are expressed as mean and standard deviation (SD).

\begin{tabular}{|c|c|c|c|}
\hline Type of Activity & Itinerary & Name of Activity & $\begin{array}{c}\text { Score } \\
\text { (Mean and SD) }\end{array}$ \\
\hline \multirow{8}{*}{ Conferences or round table } & \multirow{8}{*}{$\mathrm{A} \& \mathrm{~B}$} & Biomedical Research (round table) & $2.30 \pm 0.9$ \\
\hline & & Trauma and Orthopedic Surgery & $2.58 \pm 0.83$ \\
\hline & & Kidney transplantation & $3.02 \pm 0.9$ \\
\hline & & Otorhinolaryngology & $3.10 \pm 0.87$ \\
\hline & & Vascular Surgery & $3.15 \pm 0.74$ \\
\hline & & Radiology & $3.49 \pm 0.68$ \\
\hline & & Neurosurgery & $3.51 \pm 0.63$ \\
\hline & & Party conference & $3.59 \pm 0.75$ \\
\hline \multirow{10}{*}{ Practical workshops } & \multirow{5}{*}{$\mathrm{A}$} & Trauma and Orthopedic Surgery & $2.90 \pm 0.9$ \\
\hline & & Otorhinolaryngology Gymkhana & $3.33 \pm 0.73$ \\
\hline & & Cardiopulmonary Resuscitation & $3.39 \pm 0.71$ \\
\hline & & Surgical Skills & $3.41 \pm 0.77$ \\
\hline & & Suture & $3.67 \pm 0.54$ \\
\hline & \multirow{5}{*}{$\mathrm{B}$} & Ultrasound examination & $3.0 \pm 0.76$ \\
\hline & & Microsurgery & $3.0 \pm 0.93$ \\
\hline & & Kidney Dissection & $3.2 \pm 0.83$ \\
\hline & & Brain Dissection & $3.3 \pm 0.87$ \\
\hline & & Tracheotomy & $3.9 \pm 0.46$ \\
\hline
\end{tabular}

With respect to the practical workshops, the global assessment was $3.33 \pm 0.79$ and the results were no different when distinguishing between the " $\mathrm{A}$ " and " $\mathrm{B}$ " itineraries 
( $3.34 \pm 0.77$ vs. $3.30 \pm 0.83$, respectively). All workshops had a score equal to or greater than 3, excepting Traumatology for the "A" itinerary $2.9 \pm 0.94$. Finally, $99 \%$ considered that the surgery congress was useful for their university training and $100 \%$ would recommend it.

When analyzing the evaluation of the acquisition of transversal competencies carried out by the professor present in the Organizing Committee ( Table 3 and Figure 2), it can be seen that the students showed, from the beginning, a good level of competence in the aspects "teamwork and leadership" $(2.9 \pm 0.1)$ and "communication" $(2.7 \pm 0.1)$. On the other hand, the worst-rated competency was "planning and time management" $(0.4 \pm 0.7)$.

Table 3. Scores obtained in each of the transversal competences by the student members of the Organizing Committee. Data are expressed as mean and standard deviation (SD). Asterisk $\left(^{*}\right)$ shows the statistical differences between the first meeting and the post-congress meeting, and the pound sign (\#) shows the statistical differences between the intermediate meeting and the post-congress meeting (* or \#: $p<0.05) ;{ }^{* *}: p<0.01 ;{ }^{* * *}: p<0.001$; n.s.: $p>0.05$ ).

\begin{tabular}{cccc}
\hline Transversal Competence & First Meeting & Intermediate Meeting & Post-Congress Meeting \\
\hline Analysis and problem solving & $2.6 \pm 0.4$ & $3.2 \pm 0.2$ (n.s.) & $3.7^{*} \pm 0.1^{* * *} ; \#$ \\
\hline Teamwork and leadership & $2.9 \pm 0.1$ & $2.9 \pm 0.3$ (n.s.) & $3.6 \pm 0.1^{*} ; \#$ \\
\hline Communication & $2.7 \pm 0.1$ & $3.1 \pm 0.1$ (n.s.) & $3.4 \pm 0.2^{*}$ \\
\hline Analytical thinking & $2.2 \pm 0.4$ & $2.7 \pm 0.4$ (n.s.) & $3.2 \pm 0.5^{* *}$ \\
\hline Planning and time management & $0.4 \pm 0.7$ & $1.9 \pm 0.5$ (n.s.) & $2.9 \pm 0.5^{* * *} ; \#$ \\
\hline
\end{tabular}

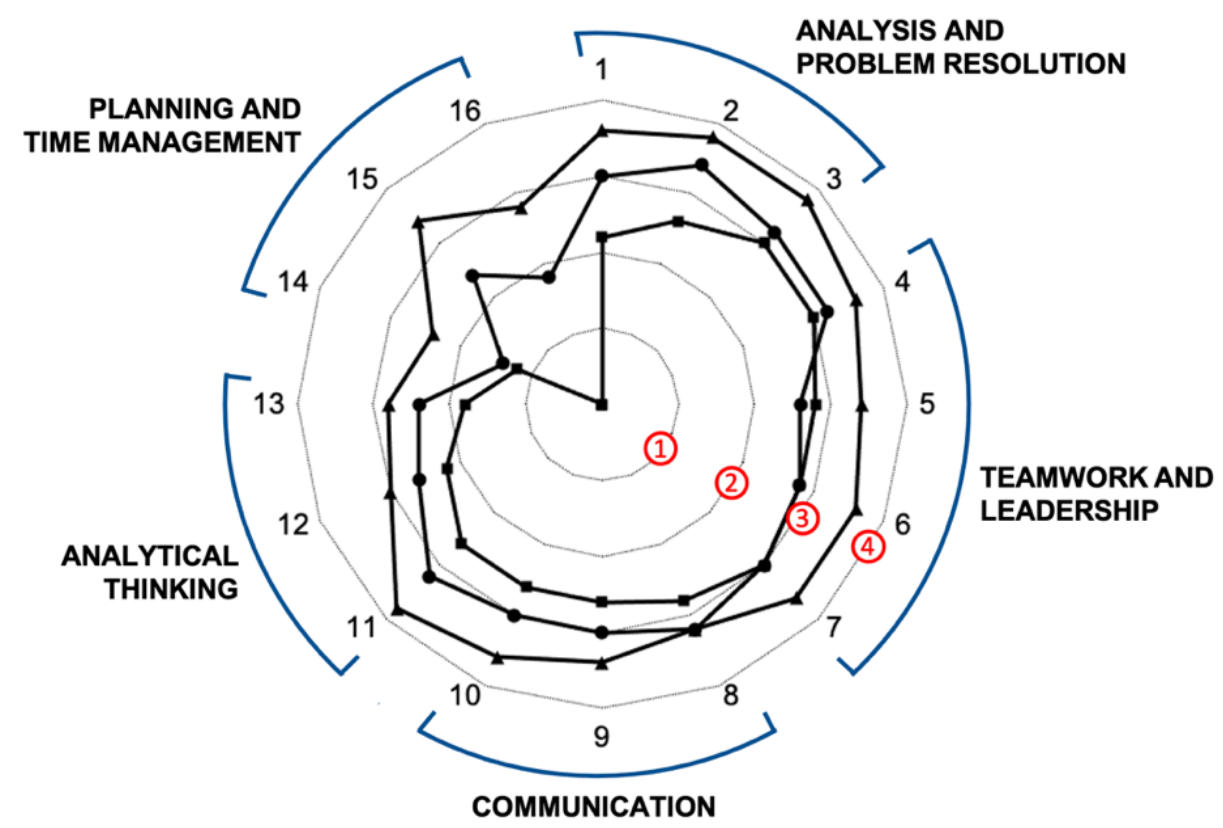

Figure 2. Radar chart analysis comparing the level of transversal competence acquisition analysis and problem solving, teamwork and leadership, communication, analytical thinking, and planning and time management using the 16-item rubric in three of the meetings held among the members of the Organizing Committee (the first meeting, square; an intermediate meeting, circle; and another meeting after the congress, triangle). The red circled numbers indicate the score between 1 and 4 . The numbers placed on the outside of the graph indicate each of the descriptors analyzed.

We noted, over the course of organizing the congress, that students exhibited a considerable increase in their transversal competences. This was particularly noticeable in the competence "planning and time management" $(2.9 \pm 0.5)$, followed to the same extent by "analysis and problem solving" $(3.7 \pm 0.1)$ and "analytical thinking" (3.2 \pm 0.5$)$. Paradoxically, the transversal competence "planning and time management" was the one that obtained the lowest percentage. 
As shown in Table 3, the most significant increases occurred when comparing the results of the first meeting with those of the third meeting (the post-congress meeting). However, when the values of the intermediate organization meeting were compared with the post-congress meeting, there was only a significant increase in the competences "analysis and problem solving", "teamwork and leadership", and "planning and time management".

\section{Discussion}

This paper presents the concept of using a student-led surgical congress for medical students as a tool for the acquisition of transversal competences. Technological and practical innovation have been progressively incorporated into medical training. Multiple educational models have relied on technological advances to develop both technical and non-technical competences and abilities at the same time. These models have two purposes: to improve the surgical technique and to improve the student's self-confidence in practice. To achieve these objectives, it has been found that the most appropriate resources are active and participative programs that involve students to a greater extent [9].

Non-technical and non-specific skills, such as leadership, teamwork, self and collective organization, decision making, autonomy, communication, and situational awareness, are a substantial part of health-related professions, such as medicine, for a competent and effective patient care [2,10]. These skills, despite being included in the catalog of transversal competencies of our institution [4], are often not worked on in sufficient depth in the curricula of health science careers, as reflected in the work of Palomares et al. [11] about the competence of communication among dentistry students at the University of the Basque Country.

Nowadays, there are many educational opportunities for the acquisition of transversal competencies in higher education. Some of these well-known methodologies are workbased projects, project work, case- and problem-based projects, etc. All of them allow students to acquire, beyond specific scientific-technical knowledge, numerous transversal competences, such as teamwork, self-solving of problems, critical analysis, active discussion of different points of view, etc. [12-14]. With respect to these aspects, our activity does not provide a clear teaching innovation. However, our model proposes a learning process that mixes first-year students (18 years of age) with sixth-year students (24 years of age or older), making it a transversal and intergenerational activity. This mixed-level learning model allows both young and old to learn from each other and allows students of all ages to share their knowledge with each other $[15,16]$.

Furthermore, active participation in congresses and other collective activities during undergraduate studies has been shown to be a key point in the training of health professionals to explore the interests of the specialty, share research, exchange experiences and transmit knowledge [17]. In a study of the National Autonomous University of Mexico with undergraduate students, those attending a general surgery course based on theoretical and practical training demonstrated improved basic surgical skills by $40 \%$. Furthermore, the error rate in both surgical material handling and basic skills was reduced to $0 \%$. Practical teaching, therefore, not only contributes to the acquisition of surgical abilities, but also causes a very significant increase in the level of self-confidence [18].

García-Núñez et al. employed a teaching strategy based on learning experience and problem-based learning. Their study design was aimed at quantifying decision-making competencies when performing diagnostic and therapeutic procedures in post-traumatic patients. To achieve this objective, they used advanced computer resources. They evaluated the results with an individual questionnaire, obtaining evidence of the acquisition of a metacognitive competence of 76\% [9]. Larraz et al. [19], when analyzing the impact of cooperative learning in the acquisition of transversal competences in teacher training students, showed that, thanks to cooperative work, students developed and increased competences involved in personal (teamwork, interpersonal relationships and ethical commitment), instrumental (verbal and written communication, problem-solving and decision-making and the ability to analyze and synthesize), and systemic skills (independent learning and 
motivation). They found that these skills were all acquired at a high level, increasing by more than $80 \%$ after active learning methodologies.

Our results show that, among the student members of the Organizing Committee, the promotion and organization of a student-led congress for medical students allowed them to increase their transversal skills. The evaluation made by the professor involved in the Organizing Committee showed that the post-congress scores of the transversal competences were 1.2-1.4 higher than those obtained at the first meeting. These values are substantially lower than those found in the aforementioned studies. However, in our opinion, there is a substantial difference that could explain these "worse" results. The evaluations made in the aforementioned papers were carried out by the students themselves, regarding their own acquisition of competencies. Several studies report that these self-assessments may often be biased and these perceptions are not always realistic $[20,21]$, so their true impact on students must be taken with caution.

Another aspect that should not be overlooked, and which requires us to be cautious in generalizing our results, is the small sample size. To date, this evaluation of the transversal competences has only been carried out on the five students involved in the organization of the third edition of the Surgery Congress for Students. On the other hand, being such a small working group, which can be constantly monitored by the professor involved in the Organizing Committee, there could be a bias in the improvement detected, and this may not be entirely due to the students' own self-learning but to involuntary interference by the professor.

When analyzing the results of the evaluation of the activities conducted during the congress, we must first point out that we used a rating scale from 1 to 4 . It is true that most studies use surveys based on a Likert scale of 1 to 5 ; in our case we opted for a scale of 1 to 4 . Since this was the first time that a survey had been conducted to evaluate such an activity promoted by the students themselves, we decided to exclude the option of answering with a neutral response, in order to obtain a complete opinion from the participants, since several studies have shown that the inclusion of a neutral or "no answer" option significantly increases the number of people who state that they have no opinion when they really do have an opinion [22,23].

This study has some limitations or difficulties that should be pointed out. Since we could not find a guide or paper detailing in detail how the students could develop by themselves, we first encountered the problem of stimulating or keeping the students focused on the organization of the congress, while maintaining their academic obligations, as these were not reduced or modified in any way by being involved in this project.

In addition, the success and development of the congress was not only dependent on the efforts and willingness of the organizing team and the rest of the staff, but also on a degree of luck whereby the complex interaction between all the aspects involved (keynote speakers, supply of consumables, budget allocation, catering, etc.) went according to plan. Many of these aspects can slip by the initial planning, without being anticipated, and therefore the students must be able to respond promptly to any unexpected events.

Another limitation is related to the evaluation, which involves two aspects, one concerning the congress and the other the Organizing Committee. Regarding the congress, in addition to seeking the feedback from the students who attended, it would also have been of interest to consider the opinion of the invited speakers and other medical specialists who were involved. The expert opinion of these people, often highly experienced in organizing and participating in congresses, would have been useful to show how the student-organized congress did or did not fit in with a professional medical congress. On the other hand, the evaluation of the acquisition of transversal competences was only carried out on the five students who were members of the Organizing Committee. This is too small a sample to clearly indicate the effectiveness of this type of activity in acquiring transversal skills. 


\section{Conclusions}

This paper presents a model of activity for the acquisition of transversal competences based on the organization of a student-led student surgical congress, ready to be implemented, and adapted and modified to the specific needs or characteristics of each institution. The positive evaluation of the activity by the attendees supports the proof of concept.

Thus, in conclusion, we consider this type of initiative to be interesting because it encourages students to learn and promotes their interest in advancing in the knowledge of surgical specialties and research in this field, as well as in the training of students in transversal competences.

Supplementary Materials: The following are available online at https:/ /www.mdpi.com/article/10 .3390/educsci11090536/s1, Table S1: Rubric for the evaluation of transversal competencies. Adapted from "Institutional Project of Transversal Competences-UPV".

Author Contributions: Conceptualization, B.H.d.I.P., F.J.S.-S. and I.G.-A.; methodology, B.H.d.l.P., M.S.-S. and F.J.S.-S.; software, B.H.d.I.P. and M.S.-S.; validation, I.G.-A., F.S. and A.S.d.R.; formal analysis, B.H.d.I.P., M.S.-S. and A.S.d.R.; investigation, B.H.d.l.P., F.J.S.-S. and M.S.-S.; writingoriginal draft preparation, B.H.d.l.P., M.S.-S. and F.J.S.-S.; writing-review and editing, B.H.d.l.P.; supervision, I.G.-A., F.S. and A.S.d.R.; project administration, B.H.d.l.P.; funding acquisition, M.S.-S. and F.J.S.-S. All authors have read and agreed to the published version of the manuscript.

Funding: The congress organization was partially supported by the Vice-rectorate of the Biscay Campus, the Student Council of the Faculty of Medicine and Nursing and the Student Council of the University of the Basque Country for their support.

Informed Consent Statement: Informed consent was obtained from all subjects involved in the study.

Data Availability Statement: The data that support the findings of this study are available from the corresponding author, (B.H.d.l.P.), upon reasonable request.

Conflicts of Interest: The authors declare no conflict of interest.

\section{References}

1. UNESCO. General Conference 1999. In Proceedings of the 30th World Conference on Higher Education for the Twenty-first Century: Vision and Action, Paris, France, 5-10 October 1998.

2. Sá, M.J.; Serpa, S. Transversal competences: Their importance and learning processes by higher education students. Educ. Sci. 2018, 8, 126. [CrossRef]

3. UNESCO. Preparing and Supporting Teachers in Asia-Pacific to Meet the Challenges of Twenty-First Century Learning; Meleisea, E., Ed.; UNESCO: Paris, France, 2016; ISBN 978-92-9223-570-3.

4. Uranga Iturrioz, M.J.; Cruz Iglesias, E.; Eizagirre Sagardia, A.I.; Gil Molina, P.; Losada Iglesias, D.; Ruiz de Gauna Bahillo, P. Catálogo de Competencias Transversales de la UPV/EHU; Servicio Editorial de la Universidad del País Vasco: Leioa, Bizkaia, Spain, 2019.

5. Palés-Argullós, J.; Nolla-Domenjó, M.; Oriol-Bosch, A.; Gual, A. Proceso de bolonia (I):Educación orientada a competencias. Educ. Medica 2010, 13, 127-135. [CrossRef]

6. COCIE 1st Congress of Surgery for Medical Students. Available online: http://www.oc.lm.ehu.eus/COCIE/COCIE2017/ (accessed on 13 August 2021).

7. COCIE 2nd Congress of Surgery for Medical Students. Available online: http:/ /www.oc.lm.ehu.es/cocie/COCIE2018/DEFAULT. htm (accessed on 13 August 2021).

8. COCIE 3rd Congress of Surgery for Medical Students. Available online: http://www.oc.lm.ehu.es/cocie/DEFAULT.htm (accessed on 13 August 2021).

9. García-Núñez, L.M.; Hernández-García, E.F; Pérez-Morales, Ó.E.; Guillén-Hernández, G.A.; Noyola-Villalobos, H.F.; GarcíaRamírez, R. Surgical education: Multichannel teaching-learning process and competences acquisition. Cir. y Cir. (English Ed.) 2019, 87, 106-112. [CrossRef]

10. Prineas, S.; Mosier, K.; Mirko, C.; Guicciardi, S. Non-technical Skills in Healthcare BT_-Textbook of Patient Safety and Clinical Risk Management; Donaldson, L., Ricciardi, W., Sheridan, S., Tartaglia, R., Eds.; Springer International Publishing: Cham, Switzerland, 2021; pp. 413-434, ISBN 978-3-030-59403-9.

11. Palomares, T.; Arteagoitia, I.; García de la Fuente, A.M.; Herrero de la Parte, B.; Bircu, D.; Ruiz de Azúa, S.; Mínguez, N. Grupo del Proyecto de Innovación Educativa 82 Development of a comprehensive plan for the acquisition of communication skills in the degree in dentistry at the university of the Basque Country: An institutional challenge. FEM Rev. la Fund. Educ. Médica 2021, $24,42-47$. 
12. Kokotsaki, D.; Menzies, V.; Wiggins, A. Project-based learning: A review of the literature. Improv. Sch. 2016, 19, $267-277$. [CrossRef]

13. Graffam, B. Active learning in medical education: Strategies for beginning implementation. Med. Teach. 2007, 29, 38-42. [CrossRef] [PubMed]

14. Frank, M.; Barzilai, A. Integrating alternative assessment in a project-based learning course for pre-service science and technology teachers. Assess. Eval. High. Educ. 2004, 29, 41-61. [CrossRef]

15. Pstross, M.; Corrigan, T.; Knopf, R.C.; Sung, H.; Talmage, C.A.; Conroy, C.; Fowley, C. The Benefits of Intergenerational Learning in Higher Education: Lessons Learned from Two Age Friendly University Programs. Innov. High. Educ. 2017, 42, 157-171. [CrossRef]

16. Gómez Cayapú, R.A.; Mayora Pernia, C.A. Suggested Guidelines to Develop Speaking Skills with Mixed-Level College Students in an English Conversation Club. Ph.D. Thesis, Universidad del Valle, Valle del Cauca, Colombia, 6 August 2019.

17. Dominic, C.; Bhalla, G. A framework for student-led education conferences. Clin. Teach. 2021, 18, 104-108. [CrossRef] [PubMed]

18. Pérez-Daniel, I.J.; Alcántara-Medina, S.; Díaz-Echevarria, A.; Jiménez-Cisneros, E.; Ruiz-Martínez, C.M.; Jiménez-Corona, J.L. Open surgery performance evaluation in undergraduate medicine students with a projection to undergo a surgical specialty training. Cir. y Cir. (English Ed.) 2018, 86, 485-490. [CrossRef]

19. Larraz, N.; Vázquez, S.; Liesa, M. Transversal skills development through cooperative learning. Training teachers for the future. Horizon 2017, 25, 85-95. [CrossRef]

20. Bouffard, T.; Narciss, S. Benefits and risks of positive biases in self-evaluation of academic competence: Introduction. Int. J. Educ. Res. 2011, 50, 205-208. [CrossRef]

21. Bouffard, T.; Boisvert, M.; Vezeau, C. The illusion of incompetence and its correlates among elementary school children and their parents. Learn. Individ. Differ. 2003, 14, 31-46. [CrossRef]

22. Nowlis, S.M.; Kahn, B.E.; Dhar, R. Coping with Ambivalence: The Effect of Removing a Neutral Option on Consumer Attitude and Preference Judgments. J. Consum. Res. 2002, 29, 319-334. [CrossRef]

23. Krosnick, J.A.; Holbrook, A.L.; Berent, M.K.; Carson, R.T.; Hanemann, W.M.; Kopp, R.J.; Mitchell, R.C.; Presser, S.; Ruud, P.A.; Smith, V.K.; et al. The Impact of "No Opinion" Response Options on Data Quality: Non-Attitude Reduction or an Invitation to Satisfice?* Public Opin. Q. 2002, 66, 371-403. [CrossRef] 